\title{
Correlações inter e intragerações e herdabilidade de cor de chips, matéria seca e produção em batata(1)
}

\author{
Andréa Felix Souza Rodrigues ${ }^{(2)}$ e Arione da Silva Pereira ${ }^{(3)}$
}

\begin{abstract}
Resumo - Os objetivos deste trabalho foram determinar correlações inter e intragerações clonais, estimar herdabilidade quanto à cor de chips, teor de matéria seca e produção de batata, e suas implicações na seleção. Duzentos e cinquienta clones de dez famílias foram escolhidos aleatoriamente de uma população de primeira geração clonal, destinada ao processamento de batatas chips, do programa de melhoramento genético de batata da Embrapa-Centro de Pesquisa Agropecuária de Clima Temperado. Os clones foram avaliados em segunda (G2), terceira (G3) e quarta (G4) gerações, respectivamente, no outono e primavera de 1999, e outono de 2000, em Pelotas, RS. Os coeficientes de correlação entre gerações e as estimativas de herdabilidade dentro das gerações clonais foram baixas em relação à cor de chips, baixas a moderadas quanto à matéria seca e incrementais com as gerações nos componentes de produção. Os coeficientes de correlação entre as características de qualidade e os componentes de produção dentro de cada geração foram baixos e, na maioria, não-significativos. As estimativas de herdabilidade dos dados conjuntos da G3 e G4 foram moderada, moderadamente alta e alta, respectivamente, em relação à cor de chips, teor de matéria seca e produção.
\end{abstract}

Termos para indexação: Solanum tuberosum, clone, seleção, método de melhoramento.

\section{Correlations between and within generations and heritability of chips color, dry matter and yield in potatoes}

\begin{abstract}
The objectives of this work were to determine correlations between and within clonal generation, to estimate heritability for chips color, dry matter content and yield of potatoes, and their implications on selection. Two hundred and fifty clones of ten families were randomly chosen from a first clonal population, directed to chips processing, of the potato breeding program of EmbrapaCentro de Pesquisa Agropecuária de Clima Temperado. The clones were evaluated in second (G2), third (G3) and fourth (G4) generations during autumn and spring of 1999 and autumn of 2000, respectively, in Pelotas, RS. The coefficients of correlation between generations and the estimates of heritability within clonal generations were low for chips color, low to moderate for dry matter and incremental with generations for yield components. The coefficients of correlations between quality and yield component traits within each generation were low and, the majority, non significant. The estimates of heritability of joint G3 and G4 data analysis were moderate, moderately high and high, respectively, for chip color, dry matter content and yield.
\end{abstract}

Index terms: Solanum tuberosum, clones, selection, breeding methods.

\section{Introdução}

Os programas de melhoramento genético de batata iniciam com o cruzamento entre duas cultivares

(1) Aceito para publicação em 4 de fevereiro de 2003 .

(2) Universidade Federal de Pelotas, Caixa Postal 354, CEP 96010-900 Pelotas, RS. E-mail: andrea.felix@zipmail.com.br

(3) Embrapa-Centro de Pesquisa Agropecuária de Clima Temperado, Caixa Postal 403, CEP 96001-970 Pelotas, RS. Bolsista do CNPq. E-mail: arione@cpact.embrapa.br (ou clones) heterozigotas. A população segregante é submetida a vários ciclos de seleção, visando à identificação de genótipos superiores (Tai, 1975). Normalmente milhares de "seedlings" são avaliados, porque durante o processo de seleção nenhum outro cruzamento é realizado, o que torna impossível a recombinação genética para obtenção do genótipo desejado (Pinto, 1999).

Com a finalidade de agilizar os programas de melhoramento genético da batata, os melhoristas têm buscado selecionar características de qualidade in- 
dustrial e produção nas primeiras gerações clonais (Maris, 1988; Bradshaw et al., 1998).

As principais características de qualidade dos tubérculos para fritura são o baixo conteúdo de açúcares redutores (glicose e frutose), que condicionam a cor dos chips, e o alto teor de matéria seca, que afeta o rendimento na industrialização de chips e a absorção de gordura durante a fritura, além da textura e do sabor (Smith, 1975).

A qualidade dos chips é controlada geneticamente, o que propicia diferenças significativas entre as cultivares (Cunningham \& Stevenson, 1963). Na obtenção de tubérculos com elevado teor de matéria seca e alta capacidade de produção de chips de cor clara, o primeiro critério é selecionar genótipos em relação a ambas características (Melo, 1999). Somente o valor fenotípico do indivíduo pode ser medido diretamente, mas é o valor genético que determina a sua influência na geração seguinte (Falconer, 1989). Portanto, a escolha de indivíduos, de acordo com seus valores fenotípicos, depende do sucesso das alterações das características da população que pode ser predito somente por intermédio do conhecimento do grau de correspondência entre o valor fenotípico e o valor genético. Como o valor da herdabilidade depende da magnitude de todos os componentes da variância, qualquer alteração em um deles afetará o valor da proporção herdável que, segundo Falconer (1989), expressa a proporção da variação total que é atribuída ao efeito genético.

Os objetivos deste trabalho foram determinar correlações inter e intragerações clonais, estimar herdabilidades quanto à cor de chips, teor de matéria seca, produção e seus componentes, e suas implicações na seleção.

\section{Material e Métodos}

Os trabalhos foram iniciados com uma amostra de 250 clones de batata de dez famílias, escolhidos aleatoriamente de uma população de primeira geração clonal, na primavera de 1998, destinada ao processamento de batatas chips, do programa de melhoramento genético de batata da Embrapa-Centro de Pesquisa Agropecuária de Clima Temperado. As combinações de genitores da amostra da população clonal estudada foram as seguintes: ND860-2/DXY-7, ND860-2/XY-14, ND860-2/385021-12, Atlantic/XY-4, E-86300/575049, E-86300/BL-2-9,
E-86300/XY-4, Ernsteltolz/104.12.13 e Ernsteltolz/DXY-15, oriundos do Centro Internacional de la Papa, Lima, Peru, e Trapeira/Atlantic, obtida na Embrapa-Centro de Pesquisa Agropecuária de Clima Temperado, Pelotas, RS. Os clones foram avaliados em segunda, terceira e quarta gerações.

Na segunda geração clonal (outono de 1999), foram avaliados 250 clones, com uma repetição, utilizando parcelas de cinco plantas. O plantio foi realizado em 24 de fevereiro de 1999 e a colheita em 27 de junho de 1999, quando as plantas estavam parcialmente secas. Na terceira geração clonal (primavera de 1999), 227 clones foram estudados em experimento delineado em blocos ao acaso, com duas repetições. A unidade experimental consistiu de dez plantas. O plantio foi feito em 17 de setembro de 1999 e a colheita em 28 de dezembro. Na quarta geração clonal (outono de 2000), foram avaliados 202 clones, utilizando um delineamento experimental de blocos ao acaso, com duas repetições de parcelas de dez plantas. O plantio foi realizado em 29 de fevereiro de 2000 e a colheita em 20 de junho de 2000.

Os clones foram cultivados no campo, num Argissolo Vermelho-Amarelo distrófico típico. Aplicou-se nos sulcos de plantio, $2.000 \mathrm{~kg} \mathrm{ha}^{-1}$ de NPK (5-30-10). A abertura dos sulcos, o plantio e a colheita foram manuais, e as práticas culturais foram as mesmas usadas em lavouras comerciais da região. $\mathrm{O}$ delineamento experimental utilizado foi blocos ao acaso. As plantas foram espaçadas com intervalos de $30 \mathrm{~cm}$ na fileira e $80 \mathrm{~cm}$ entre fileiras.

Após a colheita, os tubérculos foram curados em condições ambientais, durante duas semanas, antes da classificação, pesagem e processamento.

Nas três gerações, os clones foram avaliados quanto às seguintes características: produção, número e peso médio dos tubérculos, cor de chips e teor de matéria seca. Foram registrados o peso $(\mathrm{kg})$ e o número total de tubérculos por parcela. $\mathrm{O}$ peso médio dos tubérculos por parcela foi obtido por meio da razão entre a produção total e o número total de tubérculos.

Os chips foram preparados de amostras de três tubérculos de tamanho uniforme e sadios de cada parcela. Oito fatias de cada amostra foram lavadas em água fria, secadas em papel toalha e fritas em gordura hidrogenada vegetal a $180^{\circ} \mathrm{C}$ até cessar de borbulhar. Os chips, após drenados e esfriados, foram avaliados quanto à cor, utilizando a escala de cinco pontos (1: cor clara, 5: cor escura) da Potato Chip \& Snack Food Association, dos Estados Unidos da América do Norte.

O teor de matéria seca foi determinado segundo Association of Official Analytical Chemists (1970), com algumas modificações, e consistiu na seleção de três tubérculos, corte de duas fatias finas (2-3 mm) de cada amostra, 
uma no centro do tubérculo (sentido do diâmetro) e outra no sentido perpendicular (comprimento), redução das fatias a pequenos pedaços, os quais foram pesados em cadinhos de alumínio $(5,0 \mathrm{~g})$ e secados em estufa a vácuo, a $70^{\circ} \mathrm{C}$ por seis horas.

Os dados foram submetidos à análise estatística para obtenção dos coeficientes de variação e de correlação. Os dados combinados da terceira e quarta geração clonal foram submetidos à análise de variância para estimar os componentes de variância e herdabilidade, pelo método de Vencovsky \& Barriga (1992).

\section{Resultados e Discussão}

Os coeficientes de variação dentro das gerações clonais foram maiores quanto às características de produção do que em relação às qualidades de processamento (Tabela 1). A menor variação foi observada quanto ao teor de matéria seca, que não apresentou mudança entre as gerações. As magnitudes dos coeficientes de variação $(\mathrm{CV})$ em relação à cor dos chips e número de tubérculos aumentaram com o avanço das gerações. A produção e o peso médio de tubérculos apresentaram CV maiores na G3, provavelmente por causa da utilização de tubérculos mais uniformes, de maior número de repetições e das condições climáticas da primavera. Estes resultados indicam que a maior variação entre gerações foi devida à causas não-genéticas e, em menor grau, à causas genéticas. De acordo com Pinto et al. (1994), um dos principais fatores que limitam a eficiência de seleção nas primeiras gerações clonais é a grande variação não-genética entre os clones, em virtude do número limitado de plantas, da não utilização de repetições e do grande número de clones que são avaliados nas primeiras gerações clonais.

Em geral, os CV da G3 e G4 foram maiores do que

Tabela 1. Coeficiente de variação (\%) em relação à cor de chips, matéria seca, produção, número e peso médio de tubérculos de batata, na segunda, terceira e quarta gerações clonais. Pelotas, Embrapa-Centro de Pesquisa Agropecuária de Clima Temperado, 2000.

\begin{tabular}{lccc}
\hline Característica & \multicolumn{3}{c}{ Geração } \\
\cline { 2 - 4 } & Segunda & Terceira & Quarta \\
\hline Cor de chips $^{(1)}$ & 17,3 & 20,6 & 30,5 \\
Matéria seca (\%) & 11,1 & 9,4 & 10,6 \\
Produção de tubérculos (kg/parcela) & 32,0 & 44,9 & 40,6 \\
№ de tubérculos/parcela & 32,6 & 37,8 & 41,9 \\
Peso médio de tubérculo (g) & 28,3 & 38,4 & 30,5 \\
\hline (1)1:
\end{tabular}

da G2, provavelmente porque os tubérculos utilizados na G2 eram pouco uniformes e a parcela foi menor do que nas outras gerações. Estes resultados sugerem que uma seleção rigorosa na G2 pode ser ineficiente, quanto às características mais influenciadas por fatores ambientais, como a cor de chips, produção, número e peso médio de tubérculo.

A eficiência da seleção nas diferentes gerações clonais pode ser avaliada também pelos coeficientes de correlação entre as gerações. Assim, deveriam ser esperadas correlações altas se o comportamento dos clones fosse semelhante em todas as gerações. No presente trabalho, os coeficientes de correlação entre as gerações quanto às cinco características foram significativos, exceto em relação ao número de tubérculos entre G2 e G4 (Tabela 2). Os coeficientes foram baixos quanto à cor de chips, sugerindo que a seleção em relação à esta característica deve ser negativa, a partir da G2. Segundo Thill \& Peloquin (1995), genótipos que são indicados para o processamento na forma de chips devem apresentar-se dentro de um escore aceitável já nas primeiras gerações clonais. No presente trabalho, 24,8\% dos clones apresentaram escore de cor aceitável na G2.

As correlações quanto ao teor de matéria seca foram de magnitude moderada entre $\mathrm{G} 2$ e $\mathrm{G} 3$ e entre G3 e G4, e baixa entre G2 e G4, indicando a possibilidade de selecionar clones com intensidade moderada, a partir de G2 (Tabela 2). Os baixos coeficientes entre G2 e G4 ocorreram, provavelmente, em virtude das condições ambientais e da interação genótipo x ambiente. De acordo com Stevenson et al. (1954), freqüentemente o ambiente provoca mais alterações do que o fator genético no teor de matéria seca.

Tabela 2. Coeficientes de correlação entre gerações de seleção $(\mathrm{G})$ com relação às características de qualidade de processamento industrial e agronômica, em batata. Pelotas, Embrapa-Centro de Pesquisa Agropecuária de Clima Temperado, 2000.

\begin{tabular}{lccc}
\hline Característica & $\mathrm{G} 2 \times \mathrm{G} 3$ & $\mathrm{G} 2 \times \mathrm{G} 4$ & $\mathrm{G} 3 \times \mathrm{G} 4$ \\
\hline Cor de chips & $0,26^{(1)}$ & $0,25^{* *}$ & $0,22^{* *}$ \\
Matéria seca & $0,40^{* *}$ & $0,21^{* *}$ & $0,46^{* *}$ \\
Produção de tubérculos & $0,31^{* *}$ & $0,19^{*}$ & $0,58^{* *}$ \\
№ de tubérculos & $0,25^{* *}$ & $0,14^{\text {ns }}$ & $0,52^{* *}$ \\
Peso médio de tubérculo & $0,35^{* *}$ & $0,46^{* *}$ & $0,52^{* *}$ \\
\hline (1) 1 : cor clara, 5: cor escura. ns Não-significativo. * e **Significativo a $5 \%$ \\
e a 1\% de probabilidade, respectivamente.
\end{tabular}


Os coeficientes de correlação em relação à produção e ao peso médio dos tubérculos entre G2 e G4 e entre G2 e G3 foram significativos (Tabela 2). Comparados às demais gerações, os coeficientes de correlação entre G3 e G4 em relação aos componentes de produção foram moderadamente altos. Resultados semelhantes foram obtidos por Gopal et al. (1992), em relação à produção, entre G2 e G3, quanto ao peso médio e ao número de tubérculos, entre G2 e G3. Por sua vez, Love et al. (1997) reportaram correlações significativas entre G2 e G3 quanto à produção e número de tubérculos, e não-significativo, com relação ao peso médio. Pinto et al. (1994) observaram baixos coeficientes de correlação entre as gerações de plântulas G1 e G2 em relação aos componentes de produção. A produção de tubérculos é uma das características agronômicas que apresentam elevada variabilidade entre gerações. Depende, essencialmente, do período de crescimento e do desenvolvimento dos tubérculos; longo período de crescimento combinado com rápido desenvolvimento de tubérculos resulta em maiores produções (Maris, 1988).

Os coeficientes de correlação observados no presente trabalho sugerem que a seleção quanto à cor de chips e produção na G2 não é eficiente (Tabela 2). Entretanto, os coeficientes moderadamente altos entre G3 e G4 com relação ao teor de matéria seca, produção de tubérculos, número de tubérculos e peso médio, sugerem a possibilidade de seleção dos genótipos superiores tomando-se por base a G3, sendo o avanço de gerações realizado somente com os clones remanescentes.

As estimativas de herdabilidade dentro de cada geração foram confirmadas pelos coeficientes de correlação (Tabela 3). Cor de chips e teor de matéria seca apresentaram estimativas de herdabilidade moderada e moderadamente alta, respectivamente, nas G3 e G4. As herdabilidades dos componentes de produção aumentaram da G3 para G4, com estimativas altas na última, indicando maior eficiência na sua seleção.

As correlações entre as características de qualidade e de componentes de produção foram baixas e, na maioria, não-significativas, indicando associações reduzidas entre as mesmas (Tabela 3). Portanto, a seleção tanto em relação à cor de chips como quanto ao teor de matéria seca afetaria pouco a produção de tubérculos das plantas da amostra de população de clones selecionados. Na G2, as correlações entre

Tabela 3. Estimativas de herdabilidade e coeficientes de correlação dentro de cada geração clonal de seleção em relação a características de qualidade de processamento industrial e componentes de produção em batata. Pelotas, EmbrapaCentro de Pesquisa Agropecuária de Clima Temperado, 2000.

\begin{tabular}{|c|c|c|c|c|c|}
\hline Característica & Cor do chips & Matéria seca & Produção de tubérculos & № de tubérculos & Peso médio de tubérculos \\
\hline & \multicolumn{5}{|c|}{ Segunda geração } \\
\hline Herdabilidade & - & - & - & - & - \\
\hline Matéria seca & $-0,25^{* *}$ & - & - & - & - \\
\hline Produção de tubérculos & $-0,13^{\text {ns }}$ & $0,09^{\mathrm{ns}}$ & - & - & - \\
\hline № de tubérculos & $-0,22 * *$ & $0,10^{\mathrm{ns}}$ & $0,62^{* *}$ & - & - \\
\hline \multirow[t]{2}{*}{ Peso médio de tubérculo } & $0,12^{\mathrm{ns}}$ & $-0,02^{\mathrm{ns}}$ & $0,41^{* *}$ & $-0,42 * *$ & - \\
\hline & \multicolumn{5}{|c|}{ Terceira geração } \\
\hline Herdabilidade & 0,38 & 0,65 & 0,56 & 0,66 & 0,59 \\
\hline Matéria seca & $-0,07^{\mathrm{ns}}$ & - & - & - & - \\
\hline Produção de tubérculos & $0,10^{\mathrm{ns}}$ & $0,22^{* *}$ & - & - & - \\
\hline $\mathrm{N}^{\mathrm{o}}$ de tubérculos & $-0,02^{\mathrm{ns}}$ & $0,28^{* *}$ & $0,59^{* *}$ & - & - \\
\hline Peso médio de tubérculo & $0,14^{*}$ & $0,01^{\mathrm{ns}}$ & $0,59^{* *}$ & $-0,23 * *$ & - \\
\hline \multicolumn{6}{|c|}{ Quarta geração } \\
\hline Herdabilidade & 0,42 & 0,57 & 0,88 & 0,87 & 0,88 \\
\hline Matéria seca & $0,07^{\mathrm{ns}}$ & - & - & - & - \\
\hline Produção de tubérculos & $-0,16^{* *}$ & $-0,15^{* *}$ & - & - & - \\
\hline № de tubérculos & $-0,18^{* *}$ & $-0,09^{\mathrm{ns}}$ & $0,71^{* *}$ & - & - \\
\hline Peso médio de tubérculo & $0,06^{\mathrm{ns}}$ & $-0,11^{*}$ & $0,35^{* *}$ & $-0,35^{* *}$ & - \\
\hline
\end{tabular}

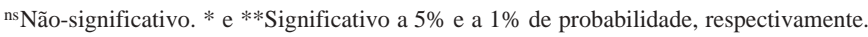


matéria seca e componentes de produção foram negativas e não-significativas. Na G3, a correlação entre cor de chips e peso médio foi positiva e, entre teor de matéria seca e componentes de produção, foram positivas e significativas. $\mathrm{Na} \mathrm{G4}$, correlações entre teor de matéria seca e componentes de produção foram negativas e não-significativas, o que indica reduzida associação entre estas características e que a seleção quanto ao alto teor de matéria seca afetaria pouco a produção, bem como o número de tubérculos e o peso médio dos mesmos. Pereira et al. (1994) também verificaram correlação negativa entre a cor de chips e a maturidade, produção total e tamanho dos tubérculos. Dessa maneira, uma seleção quanto à qualidade de chips resultaria em alterações desfavoráveis nestas características. Salamoni et al. (2000) encontraram coeficientes de correlação baixos e não-significativos entre o teor de matéria seca e as características agronômicas.

Correlações positivas e significativas entre produção de tubérculos e seus componentes têm sido relatadas (Tai, 1975), embora haja também registro de ausência ou, até mesmo, associação negativa (Birhman \& Kang, 1993). Os resultados do presente trabalho indicam que, entre as características envolvidas no desdobramento das correlações, o número e o peso médio de tubérculos foram as principais causas explicativas dos seus respectivos valores de correlação com a produção, conforme revelam seus elevados coeficientes. Assim, a maior variabilidade quanto à produção de tubérculos ocorre na G3, permitindo aplicar maior pressão de seleção.

Com frequiência, a produção tem sido altamente correlacionada com as características fenotípicas, tais como peso médio e número de tubérculos (Maris, 1988). A produção é uma característica quantitativa, governada por muitos genes, os quais afetam também outras características. Dessa forma, o conhecimento das correlações entre as características é de grande importância no direcionamento dos trabalhos de melhoramento de plantas.

Os valores estimados de herdabilidade na análise conjunta da G3 e G4 foram altos quanto à matéria seca e componentes de produção, e moderado com relação à cor de chips (Tabela 4). A herdabilidade em relação à matéria seca refletiu o alto valor da variância genética. $\mathrm{O}$ mesmo não foi observado quanto à cor de chips, que apresentou baixa herdabilidade. Assim, a seleção quanto à matéria seca apresentaria um maior ganho de seleção do que em relação à cor de chips, por apresentar maior herdabilidade e maior variância genética. Capezio et al. (1992/1993) também obtiveram valor de herdabilidade alto quanto à matéria seca, quando avaliaram dois ciclos de seleção. Cunningham \& Stevenson (1963) verificaram alta herdabilidade em relação à cor de chips, tomando por base a análise combinada da variância de 24 progênies, em dois anos de cultivo.

Quanto aos componentes de produção, as estimativas de herdabilidade foram altas, refletindo os altos valores da variância genética dos mesmos (Tabela 4). A maior herdabilidade e variância foi apresentada pelo número de tubérculos, que teria um maior ganho de seleção do que os demais componentes de produção. No entanto, diversos trabalhos têm mostrado a baixa eficiência da seleção na geração de plântula e nas primeiras gerações clonais (Anderson \& Howard, 1981; Pinto et al., 1994).

Tabela 4. Estimativas dos componentes de variância genética $\left(\sigma^{2} \mathrm{G}\right)$, interação genótipo x ambiente $\left(\sigma^{2} \mathrm{GA}\right)$, erro $\left(\sigma^{2} \mathrm{E}\right)$ e da herdabilidade $\left(\mathrm{h}^{2}\right)$ de características de qualidade de processamento e de componentes de produção de clones de batata de terceira e quarta gerações clonais. Pelotas, Embrapa-Centro de Pesquisa Agropecuária de Clima Temperado, 2000 .

\begin{tabular}{|c|c|c|c|c|}
\hline Característica & $\left(\sigma^{2} \mathrm{G}\right)$ & $\left(\sigma^{2} \mathrm{GA}\right)$ & $\left(\sigma^{2} \mathrm{E}\right)$ & $\mathrm{h}^{2}$ \\
\hline Cor de chips $^{(1)}$ & 0,12 & 0,06 & 0,25 & 0,49 \\
\hline Matéria seca (\%) & 3,24 & 0,92 & 2,47 & 0,72 \\
\hline Produção de tubérculos (kg/parcela) & 0,81 & 0,32 & 0,33 & 0,83 \\
\hline № de tubérculos por parcela & 289,74 & 157,80 & 86,90 & 0,87 \\
\hline Peso médio de tubérculo (g) & 301,24 & 73,94 & 164,27 & 0,79 \\
\hline
\end{tabular}

(1) 1: cor clara; 5: cor escura. 


\section{Conclusões}

1. Nas etapas iniciais do processo de seleção de batata, deve-se aplicar apenas uma seleção negativa quanto à cor de chips, teor de matéria seca, produção, número e peso médio de tubérculo, ou seja, eliminar somente os genótipos indesejáveis.

2. É necessário avançar até a terceira geração para poder realizar com eficiência a seleção de clones superiores quanto aos componentes de produção.

\section{Agradecimentos}

Aos funcionários Claiton Amaral Kuhn, André Luis Plá Schaun, Brenovaldo Henzel da Cruz, Osmar Kaster, Sérgio Luiz da Silva, Núbia Marilin Lettnin Ferri e Jussara Xavier dos Santos, da Embrapa-Centro de Pesquisa Agropecuária de Clima Temperado, pela colaboração prestada na execução dos experimentos; à Fapergs, pelo auxílio financeiro; ao CNPq, pelas bolsas concedidas.

\section{Referências}

ANDERSON, J. A. D.; HOWARD, H. W. Effectiveness of selection in the early stages of potato breeding programmes. Potato Research, Wageningen, v. 24, p. 289-299, 1981.

ASSOCIATION OF OFFICIAL ANALYTICAL CHEMISTS (Gaithersburg, Estados Unidos). Official methods of analysis. 11th ed. Washington, 1970. 1015 p.

BIRHMAN, R. K.; KANG, G. S. Analysis of variation and interrelationships in potato germplasm. Euphytica, Dordrecht, v. 68, p. 17-26, 1993.

BRADSHAW, J. E.; DALE, M. F. B.; SWAN, G. E. L.; TODD, D.; WILSON, R. N. Early-generation selection between and within pair crosses in a potato (Solanum tuberosum L.) breeding programme. Theoretical and Applied Genetics, Berlin, v. 97, p. 1331-1339, 1998.

CAPEZIO, S.; HUARTE, M.; CARROZZI, L. Selección por peso especifico en generaciones tempranas en el mejoramiento de la papa. Revista Latinoamericana de la Papa, Bogotá, v. 5/6, p. 54-63, 1992/1993.

CUNNINGHAM, C. E.; STEVENSON, F. J. Inheritance of factors affecting potato chip color and their association with specific gravity. American Potato Journal, Orono, v. 40, p. 253-265, 1963.

FALCONER, D. S. Introduction to quantitative genetics. 3rd ed. New York: Longman Scientific and Technical, 1989. 438 p.
GOPAL, J.; GAUR, P. C.; RANA, M. S. Early generation selection for agronomic characters in a potato breeding programme. Theoretical and Applied Genetics, Berlin, v. 84, p. 709-713, 1992.

LOVE, S. L.; WERNER, B. K.; PAVEK, J. J. Selection for individual traits in the early generations of a potato breeding program dedicated to producing cultivars with tubers having long shape and russet skin. American Potato Journal, Orono, v. 74, p. 199-312, 1997.

MARIS, B. Correlations within and between characters, between and within generations as a measure for early generation selection in potato breeding. Euphytica, Dordrecht, v. 37, p. 205-224, 1988.

MELO, P. E. Cultivares de batata potencialmente úteis para processamento na forma de fritura no Brasil e manejo para obtenção de tubérculos adequados. Informe Agropecuário, Belo Horizonte, v. 20, p. 112-119, 1999. PEREIRA, A. da S.; TAI, G. C. C.; YADA, R. Y.; TARN, T. R.; SOUZA-MACHADO, V.; COFFIN, R. H. Effect of selection for chips colour on some economic traits of potatoes. Plant Breeding, Berlin, v. 113, p. 312-317, 1994.

PINTO, C. A. B. P. Melhoramento genético da batata. Informe Agropecuário, Belo Horizonte, v. 20, p. 120-128, 1999.

PINTO, C. A. B. P.; VALVERDE, I. R. V.; ROSSI, M. S. Eficiência da seleção nas primeiras gerações clonais em batata (Solanum tuberosum L.). Pesquisa Agropecuária Brasileira, Brasília, v. 29, n. 5, p. 771-778, maio 1994.

SALAMONI, A. T.; PEREIRA, A. da S.; VIÉGAS, J.; CAMPOS, A. D.; CHALÁ, C. S. de A. Variância genética de açúcares redutores e matéria seca e suas correlações com características agronômicas em batata. Pesquisa Agropecuária Brasileira, Brasília, v. 35, n. 7, p. 1441-1445, jul. 2000.

SMITH, O. Potato chips. In: TALBURT, W. F.; SMITH, O. (Ed.). Potato processing. 3rd ed. Westport: AVI, 1975. p. 305-402.

STEVENSON, F. J.; AKELEY, R. V.; McLEAN, J. G. Potato utilization in relation to variety (heredity) and environment. American Potato Journal, Orono, v. 31, p. 327-340, 1954.

TAI, G. C. C. Effectiveness of visual selection for early clonal generation seedlings of potato. Crop Science, Madison, v. 15, p. 15-18, 1975.

THILL, A. C.; PELOQUIN, J. S. A breeding method for accelerated development of cold chipping clones in potato. Euphytica, Dordrecht, v. 84, p. 73-80, 1995.

VENCOVSKY, R.; BARRIGA, P. Genética biométrica no fitomelhoramento. Ribeirão Preto: Sociedade Brasileira de Genética, 1992. 486 p. 